\title{
BMJ Open Central nervous system (CNS) medications and polypharmacy in later life: cross-sectional analysis of the English Longitudinal Study of Ageing (ELSA)
}

\author{
Natasha Slater (D), Simon White (D), Martin Frisher
}

To cite: Slater N, White S, Frisher M. Central nervous system (CNS) medications and polypharmacy in later life: cross-sectional analysis of the English Longitudinal Study of Ageing (ELSA). BMJ Open 2020;10:e034346. doi:10.1136/ bmjopen-2019-034346

- Prepublication history for this paper is available online. To view these files, please visit the journal online (http://dx.doi org/10.1136/bmjopen-2019034346).

Received 18 September 2019 Revised 11 June 2020 Accepted 21 July 2020

Check for updates

(C) Author(s) (or their employer(s)) 2020. Re-use permitted under CC BY-NC. No commercial re-use. See rights and permissions. Published by BMJ.

School of Pharmacy, Keele University, Keele, UK

Correspondence to

Natasha Slater;

n.slater@keele.ac.uk

\section{ABSTRACT}

Objectives Many central nervous system (CNS) medications are considered potentially inappropriate for prescribing in older people; however, these medications are common in polypharmacy ( $\geq 5$ medicines) regimens. This paper aims to determine the prevalence of CNS drug classes commonly taken by older people. Furthermore, this paper aims to determine whether polypharmacy and other factors, previously found to be associated with overall polypharmacy, are associated with the most common CNS drug classes.

Design Cross-sectional study.

Setting English Longitudinal Study of Ageing (wave 6).

Participants 7730 participants ( $\geq 50$ years).

Main outcome measures Adjusted Odds Ratios (OR) and $95 \%$ confidence intervals (Cl) for CNS drug classes.

Results $31 \%$ of the sample were currently taking $\geq 5$ medications (polypharmacy), of whom 58\% ( $n=1362 / 2356$ ) were taking CNS medicines as part of their regimen. The most common CNS drug classes in polypharmacy regimens were non-opioid analgesics, opioid analgesics, tricyclic and related antidepressants (TCAs) and selective serotonin reuptake inhibitors (SSRIs) $(34.6 \%, 13.2 \%$, $10.9 \%$ and $10.4 \%$, respectively). Compared with people currently taking 1-4 prescribed medicines, polypharmacy was associated with adjusted ORs of 5.71 (95\% Cl: 4.29 to $7.61, \mathrm{p}<0.01)$ for opioid analgesics, $3.80(95 \% \mathrm{Cl}: 3.25$ to $4.44, \mathrm{p}<0.01)$ for non-opioid analgesics, $3.11(95 \% \mathrm{Cl}$ : 2.43 to $3.98, p<0.01)$ for TCAs and 2.30 (95\% Cl: 1.83 to $2.89, p<0.01$ ) for SSRIs. Lower wealth was also associated with the aforementioned CNS drug classes.

Conclusion Opioid and non-opioid analgesics were the most prevalent classes of CNS medicines in this study. Polypharmacy is strongly associated with the aforementioned classes of analgesics. Polypharmacy is also associated with TCAs and SSRIs, although to a lesser extent than for analgesics. For all CNS medicine classes, polypharmacy may need to be considered in relation to reducing the risk of potential adverse events. After adjustment, lower wealth is associated particularly with analgesics, highlighting that socioeconomic factors may play a role in the prescribing of CNS medicines. These findings provide a baseline for future research into this area.
Strengths and limitations of this study

- Detailed investigation of classes of central nervous system medicines and their associations between polypharmacy and other factors, such as age and wealth.

- This study adds to the limited literature on polypharmacy and specific medications.

- Data from a large sample of participants, with information on current medications obtained during an interview by a nurse.

- Medications were coded according to medicine class (eg, selective serotonin reuptake inhibitors); however, specific medication details (eg, fluoxetine) were not available.

- This study was cross-sectional; therefore, we cannot determine the direction of causality from our data.

\section{INTRODUCTION}

Polypharmacy (the concurrent use of multiple medicines by one individual) is becoming more prevalent worldwide. ${ }^{1}$ Previously, we reported that 'lower wealth, obesity, increasing age and the presence of chronic conditions were significantly associated with polypharmacy', among older adults $(\geq 50$ years) in England. ${ }^{2}$ The effect of these factors, on polypharmacy, is 'likely to become more pronounced' as the English population is ageing, and there are increasing numbers of individuals with multiple chronic conditions (multimorbidity). ${ }^{2}{ }^{3}$ One major risk factor of morbidity is obesity, which also continues to be a significant public health challenge. ${ }^{4}$ Furthermore, the broad gap in UK wealth inequalities persists. ${ }^{5}$ Although the aforementioned factors are associated with polypharmacy in general, little is known about whether these factors are also associated with certain types of medications in polypharmacy regimens. 
Few studies have examined the composition of polypharmacy in detail. ${ }^{67}$ Wastesson et $a l^{6}$ analysed a Swedish prescription database and reported that 'analgesics and psychotropic drugs' were commonly taken by participants with polypharmacy. The aforementioned types of medications were also shown to make a significant "contribution to the overall prevalence of polypharmacy'. Similarly, Bjerrum et al investigated whether there were any correlations between participant age and the composition of their medication regimens by analysing a Danish prescription database. Results showed that analgesics were commonly taken by older participants with polypharmacy, while younger participants with polypharmacy commonly took antidepressants. ${ }^{7}$

Although the aforementioned studies ${ }^{67}$ reported that medicines which acted on the central nervous system (CNS) were common in polypharmacy regimens; these medications are often considered to be inappropriate for prescribing in older people, due to age-related pharmacokinetic and pharmacodynamic changes. ${ }^{8}$ For example, Beers criteria ${ }^{9}$ and the screening tool of older people's prescriptions and screening tool to alert to right treatment criteria ${ }^{10}$ recommend that tricyclic antidepressants should be avoided in the elderly due to the enhancement of anticholinergic effects. Similarly, both tools recommend that benzodiazepines should be avoided in older people due to the risk of prolonged sedation and falls. ${ }^{9} 10$

There may be opportunities to deprescribe some CNS medicines in polypharmacy regimens, particularly among older people. In order to identify these opportunities, absolute and relative measures need to be calculated. Absolute measures are helpful in characterising the likelihood of an event (eg, the prevalence of polypharmacy) while relative measures (eg, ORs) provide an indication of the extent to which an event is associated with risk factors (eg, the extent to which polypharmacy is associated with CNS medicines). ${ }^{11}$ The combination of absolute and relative measures data will enable the associations between polypharmacy and CNS medicines to be examined in detail. ${ }^{11}$

The aim of this study was first, to determine the prevalence of CNS drug classes commonly taken by older people ( $\geq 50$ years). The second aim was to determine whether polypharmacy and other factors, previously found to be associated with overall polypharmacy, are associated with the most common CNS drug classes.

\section{METHODS}

\section{Sample and participants}

The English Longitudinal Study of Ageing (ELSA) started collecting data in 2002 from a broadly representative sample of the English population, who were aged over $50 .{ }^{12}$ Since then, data have been collected in faceto-face interviews and by the completion of written questionnaires every 2 years. ${ }^{12}$ Data have also been collected during nurse assessments which have taken place every 4years. ${ }^{12}$ This cross-sectional study analysed data collected between May 2012 and June 2013 (ELSA wave 6).

Overall, 10601 older adults provided data at wave 6 . Most of the participants $(86.5 \%, \mathrm{n}=9169 / 10601)$ at wave 6 were classified as core participants. Core participants are individuals who meet the following three criteria: they must have been living in the household at the time of the Health Survey for England, they must meet the age criteria of a given ELSA cohort ( $\geq 50$ years) and they must have provided data in the first wave of ELSA, once invited to participate in the study. ${ }^{13}$ Of the core participants at wave $6,84.3 \%(\mathrm{n}=7730 / 9169)$ completed the nurse interview and the latter group are the focus of the current study.

\section{Patient and public involvement}

No patients were involved in the development of the research question, study design or data interpretation in this study.

\section{Ethical approval}

The National Research and Ethics Committee have ethically approved all ELSA waves under the National Research and Ethics Service (NRES). Informed written consent has been provided by all ELSA participants, and their data are stored anonymously. ${ }^{14}$ ELSA data can be accessed via the UK Data Service Discover. ${ }^{15}$ Participants were not involved in the current study; therefore, additional ethical approval was not necessary.

\section{Inclusion criteria}

Core participants must have successfully completed a nurse assessment, a face-to-face interview, and a written questionnaire at wave 6 to be eligible for inclusion in the current study.

\section{Data collection}

Details about current medication usage were collected during the nurse assessment. Participants were asked 'Could I take down the names of the medicines, including pills, syrups, ointments, puffers or injections, prescribed for you by a doctor or a nurse?'. ${ }^{16}$ The nurse interviewer then verified participant answers by asking to see the original medication container and sought to determine whether the medication was current by asking 'Have you taken/used the medication in the last 7 days?' ${ }^{16}$ All current medication details were converted into a six-digit code by the nurse interviewer, according to the British National Formulary (Edition 61) chapter and subsection. ${ }^{17}$ For example, non-opioid analgesics were coded as 040701, where the first two digits represented the BNF chapter (Chapter 4-CNS), the next two digits represented the type of medication (analgesics) and the final two digits represented the medication class. ${ }^{18}$ The nurse interviewer coded up to 27 different prescribed medicines per participant. ${ }^{19}$

In addition to gathering information about current medication usage, the nurse interviewer recorded demographic data and took a number of measurements, 
including weight and height. ${ }^{16}$ These measurements were used to calculate each participants body mass index (BMI). In the current study, obesity was defined as a BMI $\geq 30 \mathrm{~kg} / \mathrm{m}^{2}$; overweight weight was defined as a BMI between $25.0 \mathrm{~kg} / \mathrm{m}^{2}$ and $29.9 \mathrm{~kg} / \mathrm{m}^{2}$; normal weight was defined as a BMI between $18.5 \mathrm{~kg} / \mathrm{m}^{2}$ and $24.9 \mathrm{~kg} / \mathrm{m}^{2}$ and underweight was defined as a BMI $\leq 18.5 \mathrm{~kg} / \mathrm{m}^{2}{ }^{20}$

Further demographical data and health data were collected by trained interviewers during the face-to-face interviews. Participants were asked the following question 'Do you have any long-standing illness, disability or infirmity?' and answers were recorded as 'yes' or 'no'. ${ }^{21}$ Data about monies received through employment, pensions, benefits, savings and investments were also collected by the interviewers. ${ }^{21}$ Participants provided information about their physical assets too. With the exception of pension wealth, household wealth was calculated by summating the aforementioned financial data less any debts (eg, mortgage). Household wealth data were used when allocating participants to a wealth quintile, where quintile 1 was highest wealth and quintile 5 was lowest wealth.

Finally, participants provided information regarding their lifestyle choices over the past 12 months in the face-to-face interview and written questionnaire. ${ }^{21}{ }^{22}$ Rare alcohol consumption was defined as drinking alcohol less than two times a month, frequent alcohol consumption was defined as drinking alcohol between one and four times per week; whereas, very frequent alcohol was defined as drinking alcohol more than five times per week. ${ }^{23}$ Smoking habits over the past 12 months were ascertained and participants were categorised as either smokers, ex-smokers or non-smokers.

\section{Definitions}

Polypharmacy was defined as five or more currently prescribed medications, while non-polypharmacy was defined as one to four currently prescribed medications. These definitions have been used in other studies. ${ }^{24}$

\section{Data analysis}

Participants were allocated to one of the following three groups according to the number of prescribed medicines they were currently taking: no medicines, 1-4 medicines (non-polypharmacy) and $\geq 5$ medicines (polypharmacy). Each group were profiled according to participant demographics. Participants taking no current medicines were excluded from the main analyses. Descriptive statistics were used to profile current medication usage according to BNF chapters. ${ }^{17}$ Following this, the most common BNF Chapter 4 (CNS) drug classes were identified. Logistic regression was used to determine the adjusted ORs for the associations between polypharmacy and the most common CNS drug classes. Additionally, logistic regression was used to determine whether the factors associated with polypharmacy in general, were also associated with the most common CNS drug classes. The following drug classes were selected because they were taken by at least $10 \%$ of participants with polypharmacy: non-opioid analgesics, opioid analgesics, tricyclic and related antidepressants (TCAs) and selective serotonin reuptake inhibitors (SSRIs). ORs with corresponding 95\% CIs were calculated for the aforementioned CNS drug classes. All models were adjusted for the following covariates: polypharmacy, age, gender, the presence of long-standing conditions, BMI, smoking, alcohol consumption over the past 12 months and wealth. The minimum sample size required for the models was $230 .^{25}$ Missing data were coded as 'missing' and were included (but not reported) as a separate category in the models. ${ }^{26} \mathrm{~A} p$ value of 0.05 or less was considered to be statistically significant. All analyses were undertaken using SPSS V.24.0.

\section{RESULTS}

\section{Participant characteristics}

Of the 7730 study participants, $30.5 \%$ (n=2356/7730) were currently taking five or more prescribed medicines (polypharmacy), while $45.7 \%$ ( $n=3532 / 7730)$ were currently taking between one and four prescribed medicines (nonpolypharmacy) (table 1). Participants with polypharmacy were older (mean age 68.6 years) in comparison to participants with non-polypharmacy (mean age 66.1 years) and participants taking no medicines (mean age 62.1 years). There were also more women than men in all groups (table 1).

Participants provided further details about their current medication usage during the nurse interview at wave 6 . Results are presented in terms of BNF chapters in table $1 .{ }^{17}$ Cardiovascular medicines (BNF Chapter 2) were taken by $90.6 \% \quad(n=2135 / 2356)$ of participants with polypharmacy. Other common types of medications taken by participants with polypharmacy included gastrointestinal medicines (BNF Chapter 1), CNS medicines (BNF Chapter 4) and endocrine medicines (BNF Chapter 6) (54.0\%, 57.8\% and $45.6 \%$, respectively) (table 1). In comparison to the polypharmacy group, fewer participants in the non-polypharmacy group were taking cardiovascular medicines (BNF Chapter 2), CNS medicines (BNF Chapter 4), gastrointestinal medicines (BNF Chapter 1) and endocrine medicines (BNF Chapter 6) $(58.6 \%, 23.8 \%, 18.5 \%$ and $19.7 \%$ respectively) (table 1$)$.

Medications which acted on the CNS were the focus of the current study; therefore, BNF Chapter 4 data were stratified according to drug class (table 2). Non-opioid analgesics were taken by $34.6 \%(n=816 / 2356)$ of participants with polypharmacy. Other common drug classes taken by participants with polypharmacy included opioid analgesics, TCAs and SSRIs $(13.2 \%, 10.9 \%$ and $10.4 \%$, respectively) (table 2). The aforementioned drug classes were also most commonly taken by participants in the non-polypharmacy group; however, they were taken by fewer participants $(8.9 \%, 2.0 \%, 3.5 \%$ and $5.2 \%$, respectively) (table 2).

Logistic regression was used to determine the adjusted ORs for the associations between polypharmacy and the 
Table 1 Participant characteristics at wave $6(n=7730)$

\begin{tabular}{|c|c|c|c|}
\hline Participant characteristics & $\begin{array}{l}\text { Participants with no } \\
\text { medicines ( } n=1842) \\
(\%)\end{array}$ & $\begin{array}{l}\text { Participants with } 1-4 \\
\text { medicines ( } \mathrm{n}=3532)(\%) \\
\text { (non-polypharmacy) }\end{array}$ & $\begin{array}{l}\text { Participants with } \geq 5 \\
\text { medicines ( } n=2356)(\%) \\
\text { (polypharmacy) }\end{array}$ \\
\hline \multicolumn{4}{|l|}{ Age (years) } \\
\hline $50-59$ & $732(39.7)$ & 719 (20.4) & $244(10.4)$ \\
\hline $60-69$ & $802(43.5)$ & $1482(42.0)$ & $728(30.8)$ \\
\hline $70-84$ & $281(15.3)$ & $1174(33.2)$ & $1170(49.7)$ \\
\hline$\leq 85$ & $27(1.5)$ & $157(4.4)$ & $214(9.1)$ \\
\hline \multicolumn{4}{|l|}{ Gender } \\
\hline Male & $860(46.7)$ & $1536(43.5)$ & $1052(44.7)$ \\
\hline Female & $982(53.3)$ & $1996(56.5)$ & $1304(55.3)$ \\
\hline \multicolumn{4}{|l|}{ Long-standing condition } \\
\hline No & $1432(77.7)$ & $1621(45.9)$ & $388(16.5)$ \\
\hline Yes & 410 (22.3) & $1911(54.1)$ & $1968(83.5)$ \\
\hline \multicolumn{4}{|l|}{ BMI } \\
\hline $\mathrm{BMI}<18.5 \mathrm{~kg} / \mathrm{m}^{2}:$ underweight & $15(0.8)$ & $34(1.0)$ & $20(0.8)$ \\
\hline BMI $18.5-24.9 \mathrm{~kg} / \mathrm{m}^{2}:$ normal & $645(35.0)$ & $892(25.3)$ & $421(17.9)$ \\
\hline BMI $25.0-29.9 \mathrm{~kg} / \mathrm{m}^{2}$ : overweight & $757(41.1)$ & $1485(42.0)$ & $787(33.4)$ \\
\hline $\mathrm{BMI}>30 \mathrm{~kg} / \mathrm{m}^{2}:$ obese & $397(21.6)$ & 995 (28.2) & $935(39.7)$ \\
\hline \multicolumn{4}{|l|}{ Alcohol consumption in past 12 months } \\
\hline Never & $130(7.1)$ & $350(9.9)$ & $442(18.8)$ \\
\hline Rarely & $221(12.0)$ & $518(14.7)$ & $412(17.5)$ \\
\hline Frequently & $670(36.4)$ & $1154(32.7)$ & $643(27.3)$ \\
\hline Very frequently & 669 (36.3) & $1212(34.3)$ & $579(24.6)$ \\
\hline \multicolumn{4}{|l|}{ Smoking } \\
\hline Never smoked & $816(44.3)$ & $1396(39.5)$ & $694(29.5)$ \\
\hline Ex-smoker & $784(42.6)$ & $1784(50.5)$ & $1364(57.9)$ \\
\hline Current smoker & $242(13.1)$ & $352(10.0)$ & $298(12.6)$ \\
\hline \multicolumn{4}{|l|}{ Wealth } \\
\hline Wealth quintile 1 (highest wealth) & $506(27.5)$ & 857 (24.3) & $380(16.1)$ \\
\hline Wealth quintile 2 & $429(23.3)$ & $791(22.4)$ & $453(19.2)$ \\
\hline Wealth quintile 3 & $356(19.3)$ & $704(19.9)$ & $492(20.9)$ \\
\hline Wealth quintile 4 & $262(14.2)$ & $615(17.4)$ & $575(24.4)$ \\
\hline Wealth quintile 5 (lowest wealth) & $243(13.2)$ & $489(13.8)$ & $432(18.3)$ \\
\hline \multicolumn{4}{|l|}{$\begin{array}{l}\text { Currently prescribed medications by BNF } \\
\text { chapter }^{17}\end{array}$} \\
\hline BNF Chapter 1 (gastrointestinal system) & & $653(18.5)$ & $1273(54.0)$ \\
\hline BNF Chapter 2 (cardiovascular system) & & $2071(58.6)$ & 2135 (90.6) \\
\hline BNF Chapter 3 (respiratory system) & & $404(11.4)$ & 738 (31.3) \\
\hline BNF Chapter 4 (central nervous system) & & $842(23.8)$ & $1362(57.8)$ \\
\hline BNF Chapter 5 (infections) & & $104(2.9)$ & $163(6.9)$ \\
\hline BNF Chapter 6 (endocrine system) & & $696(19.7)$ & $1075(45.6)$ \\
\hline $\begin{array}{l}\text { BNF Chapter } 7 \text { (obstetrics, gynaecology and } \\
\text { urinary tract disorders) }\end{array}$ & & $182(5.2)$ & $336(14.3)$ \\
\hline $\begin{array}{l}\text { BNF Chapter } 8 \text { (malignant disease and } \\
\text { immunosuppression) }\end{array}$ & & $54(1.5)$ & $66(2.8)$ \\
\hline BNF Chapter 9 (nutrition and blood) & & $248(7.0)$ & $576(24.4)$ \\
\hline $\begin{array}{l}\text { BNF Chapter } 10 \text { (musculoskeletal and joint } \\
\text { diseases) }\end{array}$ & & 359 (10.2) & 617 (26.2) \\
\hline
\end{tabular}


Table 1 Continued

\begin{tabular}{|c|c|c|}
\hline Participant characteristics (\%) & (non-polypharmacy) & (polypharmacy) \\
\hline BNF Chapter 11 (eye) & $124(3.5)$ & $262(11.1)$ \\
\hline BNF Chapter 12 (ear, nose and oropharynx) & $87(2.5)$ & $168(7.1)$ \\
\hline
\end{tabular}

BMI, body mass index; BNF, British National Formulary.

most common CNS drug classes. Additionally, logistic regression was used to determine whether the factors associated with polypharmacy, in general, were also associated with the most common CNS drug classes. The following CNS drug classes were selected because they were taken by at least $10 \%$ of participants with polypharmacy: non-opioid analgesics, opioid analgesics, TCAs and SSRIs (table 2). All models were adjusted for polypharmacy, age, gender, the presence of long-standing conditions, BMI, smoking, alcohol consumption and wealth. Logistic regression results are presented in table 3.

\section{DISCUSSION}

The most prevalent CNS drug classes taken by study participants ( $\geq 50$ years) were non-opioid analgesics, opioid analgesics, TCAs and SSRIs $(19.2 \%, 6.5 \%, 6.5 \%$ and $7.3 \%$, respectively). The prevalence of CNS drug classes was also considered in relation to polypharmacy. In the current study, there were 2356 participants with polypharmacy ( $\geq 5$ prescribed medicines), of whom $57.8 \%(\mathrm{n}=1362)$ were currently taking CNS medicines.
In contrast, fewer participants in the non-polypharmacy group (1-4 prescribed medicines) were currently taking CNS medicines $(23.8 \%, \mathrm{n}=842 / 3532)$.

Polypharmacy was associated with an adjusted OR of 5.71 (95\% CI: 4.29 to $7.61, \mathrm{p}<0.01)$ for opioid analgesics and 3.80 (95\% CI: 3.25 to $4.44, \mathrm{p}<0.01$ ) for nonopioid analgesics. These findings advance the existing literature by showing the magnitude of the association between polypharmacy and analgesics. ${ }^{627}$ One explanation offered for the aforementioned association is that pain commonly co-exists with other chronic conditions, and polypharmacy may be used to manage these morbidities. $^{28} 29$ However, this approach may increase an individual's exposure to the adverse effects associated with analgesics, as polypharmacy increases the opportunity for drug-drug interactions and adverse drug reactions to occur. ${ }^{3031}$ Further work is needed to explore alternative reasons why individuals with polypharmacy are three to four times more likely to be taking analgesics as part of their medication regimen, compared with individuals in the non-polypharmacy group.

Table 2 Current usage of BNF Chapter 4 (central nervous system) medications by drug class $(n=5888)$

BNF Chapter 4 (central nervous system) $)^{17}$

\begin{tabular}{|c|c|c|}
\hline BNF Chapter 4 (central nervous system) ${ }^{17}$ & $\begin{array}{l}\text { Participants with 1-4 } \\
\text { medicines ( } n=3532)(\%) \\
\text { (non-polypharmacy) }\end{array}$ & $\begin{array}{l}\text { Participants with } \geq 5 \\
\text { medicines }(n=2356)(\%) \\
\text { (polypharmacy) }\end{array}$ \\
\hline Non-opioid analgesics & $313(8.9)$ & $816(34.6)$ \\
\hline Opioid analgesics & $69(2.0)$ & $311(13.2)$ \\
\hline Tricyclic and related antidepressant drugs & $123(3.5)$ & $258(10.9)$ \\
\hline Selective serotonin reuptake inhibitors & $185(5.2)$ & $246(10.4)$ \\
\hline Hypnotics & $31(0.9)$ & $103(4.4)$ \\
\hline Drugs used in nausea and labyrinth disorders & $44(1.2)$ & $101(4.2)$ \\
\hline Other antidepressant drugs & $31(0.9)$ & $82(3.5)$ \\
\hline Drugs for the treatment of Parkinson's disease & $27(0.8)$ & $44(1.9)$ \\
\hline Drugs for the treatment of neuropathic pain & $11(0.3)$ & $24(1.0)$ \\
\hline Drugs for the treatment of dementia & $9(0.3)$ & $10(0.4)$ \\
\hline Drugs for the treatment of dependence (alcohol, nicotine and opioid) & $8(0.2)$ & $9(0.4)$ \\
\hline Drugs for the treatment of dystonia and other involuntary movements & $13(0.3)$ & $7(0.3)$ \\
\hline
\end{tabular}


Table 3 Logistic regression to determine the associations between polypharmacy, participant characteristics and the usage of non-opioid analgesics, opioid analgesics, TCAs and SSRIs in ELSA participants $(n=5888)$

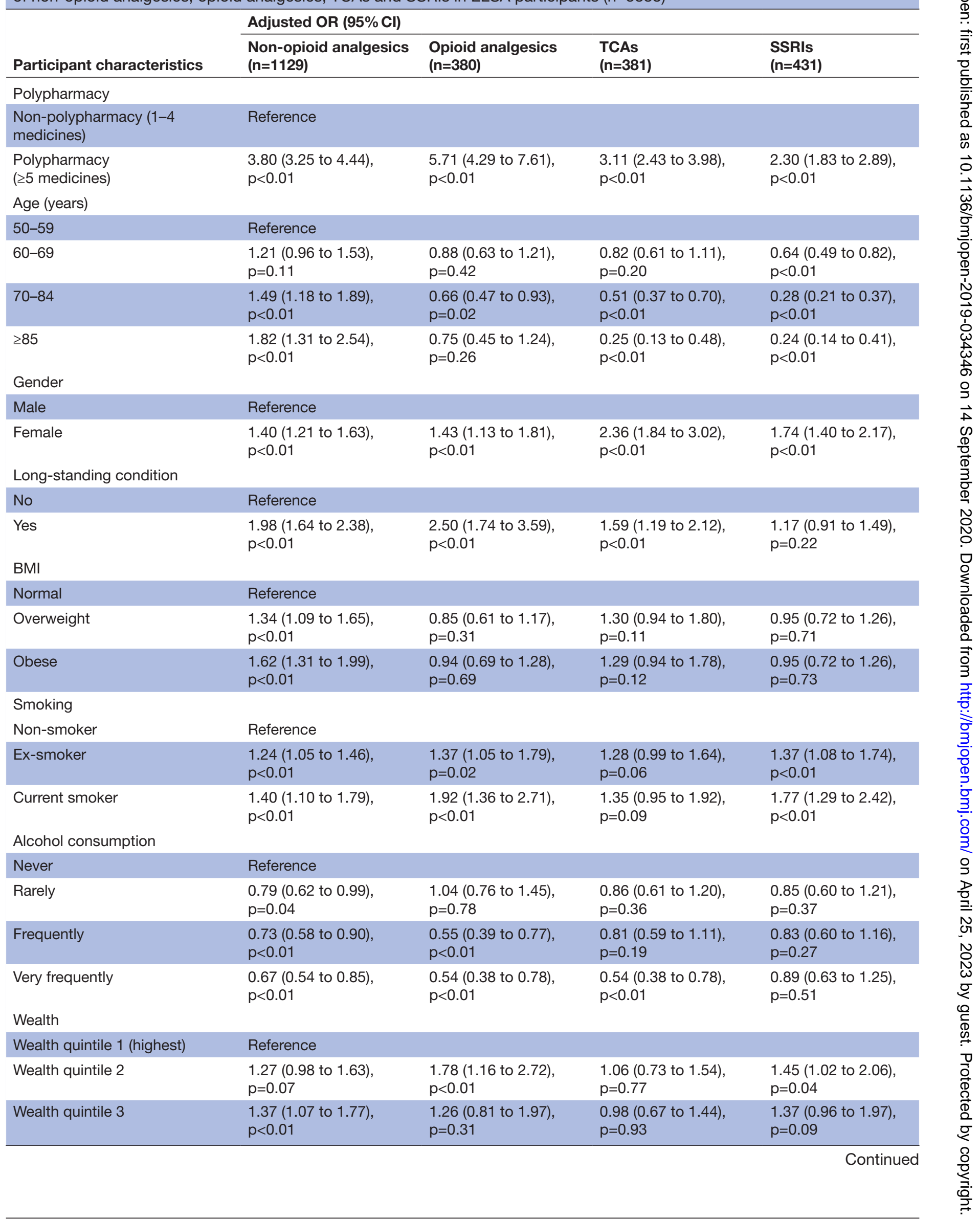




\begin{tabular}{|c|c|c|c|c|}
\hline \multirow[b]{2}{*}{ Participant characteristics } & \multicolumn{4}{|l|}{ Adjusted OR $(95 \% \mathrm{Cl})$} \\
\hline & $\begin{array}{l}\text { Non-opioid analgesics } \\
(n=1129)\end{array}$ & $\begin{array}{l}\text { Opioid analgesics } \\
(n=380)\end{array}$ & $\begin{array}{l}\text { TCAs } \\
(n=381)\end{array}$ & $\begin{array}{l}\text { SSRIs } \\
(n=431)\end{array}$ \\
\hline Wealth quintile 5 (lowest) & $\begin{array}{l}2.40 \text { ( } 1.86 \text { to } 3.12) \\
p<0.01\end{array}$ & $\begin{array}{l}2.49(1.63 \text { to } 3.80) \\
p<0.01\end{array}$ & $\begin{array}{l}1.52(1.05 \text { to } 2.21), \\
p=0.03\end{array}$ & $\begin{array}{l}1.55(1.07 \text { to } 2.23), \\
p=0.02\end{array}$ \\
\hline
\end{tabular}

Models adjusted for: polypharmacy, age, gender, the presence of long-standing conditions, BMI, smoking, alcohol consumption and wealth.

BMI, body mass index; ELSA, English Longitudinal Study; SSRIs, selective serotonin reuptake inhibitors; TCAs, tricyclic and related antidepressant drugs.

Findings also showed that polypharmacy was associated with an adjusted OR of 3.11 (95\% CI: 2.43 to 3.98, $\mathrm{p}<0.01$ ) for TCAs and 2.30 (95\% CI: 1.83 to 2.89, $\mathrm{p}<0.01)$ for SSRIs. It is difficult to compare these findings to the existing literature because a recent systematic review showed that 'there is almost no data available on antidepressant prescribing in older adults treated with polypharmacy, ${ }^{32}$

Logistic regression showed that other factors, including age, gender and wealth, were also associated with the most common CNS drug classes. Individuals aged over 60 years were less likely to take opioid analgesics, TCAs and SSRIs, compared with individuals aged 50-59 years. Low prioritisation of pain, fears about opioid side effects and concerns about tolerance or dependence, are some of the reasons previously cited to explain why older people are less likely to take opioid analgesics in their medication regimens. ${ }^{33}$ However, our findings, in relation to age and antidepressant usage, are different to those reported in previous studies thus, requiring further exploration. ${ }^{34} 35$

Women were more likely to take analgesics, TCAs and SSRIs, compared with men. Craftman et $a l^{36}$ reported similar findings when they examined medication usage in older adults, over a 20-year period. One possible explanation for our analgesic findings could be that there are gender differences in relation to pain. Pain is more prevalent in women, and often reported to be more severe, compared with men; however, the underlying aetiology is not fully understood. ${ }^{37}$

Lower wealth was associated with non-opioid analgesics (adjusted OR 2.40; 95\% CI: 1.86 to 3.12, p<0.01) and opioid analgesics (adjusted OR 2.49; 95\% CI: 1.63 to $3.80, \mathrm{p}<0.01)$. High levels of unemployment, high prevalence of chronic pain and limited access to specialist pain services, in deprived socioeconomic areas, have been previously cited as reasons behind the association between lower wealth and analgesics. ${ }^{38}{ }^{39}$ It has also been suggested that among people with lower socioeconomic status (SES), disability rates are higher when compared with people with higher SES reporting the same intensity of pain ${ }^{40}$ Lower wealth was also associated with TCAs (adjusted OR 1.52; 95\% CI: 1.05 to 2.21, $\mathrm{p}=0.03$ ) and SSRIs (adjusted OR 1.55; 95\% CI: 1.07 to 2.23, $\mathrm{p}=0.02$ ).
While we acknowledge that TCAs and SSRIs are not always indicated for the treatment of depression, these findings complement previously published research, which showed that lower wealth was significantly associated with depression in ELSA participants. ${ }^{41}$

This study has some key strengths. Data from 7730 participants were included in our analyses. Moreover, this is the first study to examine the associations between polypharmacy and CNS medicines, in detail, by examining absolute and relative measures. Our analyses also enabled us to examine the associations between the most common CNS drug classes and a wide range of other factors. Furthermore, the potential for residual confounding was minimised by adjusting for a range of health, lifestyle and economic covariates in our analyses.

Despite the aforementioned strengths, this study has several limitations. This study was cross-sectional; therefore, we cannot determine the direction of causality from our data. Furthermore, the nurse interviewer coded participant's medications according to BNF chapter and drug class (eg, SSRIs); however, they were unable to record specific medication (eg, fluoxetine) or combination medication data. This may need to be taken into consideration when future work is conducted into CNS medicines and polypharmacy.

Opioid and non-opioid analgesics were the most prevalent classes of CNS medicines in this study. Polypharmacy is strongly associated with the aforementioned classes of analgesics. Polypharmacy is also associated with TCAs and SSRIs, although to a lesser extent than for analgesics. For all CNS medicine classes, polypharmacy may need to be considered in relation to reducing the risk of potential adverse events. After adjustment, lower wealth is associated particularly with analgesics, highlighting that socioeconomic factors may play a role in the prescribing of CNS medicines. These findings provide a baseline for future research into this area.

Acknowledgements The authors would like to thank the ELSA participants, the ELSA researchers and the UK Data Service for enabling the use of ELSA data for in our analyses.

Contributors NS, MF and SW contributed to the study idea. NS led the study. Data analysis was conducted by NS and MF, who had full access to wave 6 ELSA data, 
supplied by the UK Data Service and they take full responsibility for the integrity and accurate analysis of data. All authors contributed to data interpretation. NS drafted the manuscript with contributions from MF and SW. NS and MF are the guarantors for this study.

Funding The authors have not declared a specific grant for this research from any funding agency in the public, commercial or not-for-profit sectors.

Competing interests None declared.

Patient and public involvement Patients and/or the public were not involved in the design, or conduct, or reporting, or dissemination plans of this research.

Patient consent for publication Not required.

Provenance and peer review Not commissioned; externally peer reviewed.

Data availability statement Anonymous ELSA data are publicly available from UK Data Service Discover https://discover.ukdataservice.ac.uk/. No additional data were available for this study.

Open access This is an open access article distributed in accordance with the Creative Commons Attribution Non Commercial (CC BY-NC 4.0) license, which permits others to distribute, remix, adapt, build upon this work non-commercially, and license their derivative works on different terms, provided the original work is properly cited, appropriate credit is given, any changes made indicated, and the use is non-commercial. See: http://creativecommons.org/licenses/by-nc/4.0/.

\section{ORCID iDs}

Natasha Slater http://orcid.org/0000-0002-7000-1995

Simon White http://orcid.org/0000-0003-0096-251X

\section{REFERENCES}

1 Bushardt RL, Massey EB, Simpson TW, et al. Polypharmacy: misleading, but manageable. Clin Interv Aging 2008;3:383-9.

2 Slater N, White S, Venables R, et al. Factors associated with polypharmacy in primary care: a cross-sectional analysis of data from the English longitudinal study of ageing (ELSA). BMJ Open 2018;8:e020270.

3 The King's Fund. Long-Term conditions and multi-morbidity, 2015. Available: https://www.kingsfund.org.uk/projects/time-thinkdifferently/trends-disease-and-disability-long-term-conditions-multimorbidity [Accessed 12 Dec 2019].

$4 \mathrm{Pi}$-Sunyer $\mathrm{X}$. The medical risks of obesity. Postgrad Med 2009;121:21-33.

5 The Equality Trust. The scale of economic inequalities in the UK, 2019. Available: https://www.equalitytrust.org.uk/scale-economicinequality-uk [Accessed 29 Jan 2019].

6 Wastesson JW, Cedazo Minguez A, Fastbom J, et al. The composition of polypharmacy: a register-based study of Swedes aged 75 years and older. PLoS One 2018;13:e0194892.

7 Bjerrum L, Søgaard J, Hallas J, et al. Polypharmacy: correlations with sex, age and drug regimen. A prescription database study. Eur J Clin Pharmacol 1998;54:197-202.

8 Mangoni AA, Jackson SHD. Age-Related changes in pharmacokinetics and pharmacodynamics: basic principles and practical applications. Br J Clin Pharmacol 2004;57:6-14.

9 By the 2019 American Geriatrics Society Beers Criteria ${ }^{\circledR}$ Update Expert Panel. American geriatrics Society 2019 updated AGS beers Criteria $®$ for potentially inappropriate medication use in older adults. J Am Geriatr Soc 2019;67:674-94.

10 O'Mahony D, O'Sullivan D, Byrne S, et al. STOPP/START criteria for potentially inappropriate prescribing in older people: version 2. Age Ageing 2015;44:213-8.

11 Noordzij M, van Diepen M, Caskey FC, et al. Relative risk versus absolute risk: one cannot be interpreted without the other. Nephrol Dial Transplant 2017;32:ii13-18.

12 Steptoe A, Breeze E, Banks J, et al. Cohort profile: the English longitudinal study of ageing. Int J Epidemiol 2013;42:1640-8.

13 Banks J, Nazroo J, Steptoe A. The dynamics of ageing: evidence from the English longitudinal study of ageing 2002-12 (wave 6).

14 English longitudinal study of ageing (ELSA) wave 1 to wave 6. Available: http://doc.ukdataservice.ac.uk/doc/5050/mrdoc/pdf/5050_ elsa user guide waves 1-6 v3.pdf [Accessed 6 Aug 2019].

15 UK Data Service Discover. English longitudinal study of ageing. Available: https://discover.ukdataservice.ac.uk/series/?sn=200011 [Accessed 1 Aug 2019].
16 Nat Cen Social Research. English longitudinal study of ageing wave 6 nurse questionnaire. 2012-2013. Available: https://www. elsa-project.ac.uk/uploads/elsa/docs_w6/nurse_documentation.pdf [Accessed 12 Jun 2019].

17 Open Prescribing. All BNF sections. Available: https:// openprescribing.net/bnf/ [Accessed 6 Aug 2019].

18 Dhalwani NN, Fahami R, Sathanapally H, et al. Association between polypharmacy and falls in older adults: a longitudinal study from England. BMJ Open 2017;7:e016358.

19 English Longitudinal Study of Ageing (ELSA). Nurse user guide. Available: ttp://doc.ukdataservice.ac.uk/doc/8346/mrdoc/pdf/8346_ waves_2-4-6-8_nurse_data_user_guide_v01.pdf [Accessed 5 Aug 2019].

20 National Health Service. Obesity overview. Available: https://www. nhs.uk/conditions/obesity/ [Accessed 4 May 2019].

21 Nat Cen Social Research. English longitudinal study of ageing wave 6 interview questionnaire. version 3.0. Available: https://www. elsa-project.ac.uk/uploads/elsa/docs_w6/main questionnaire.pdf [Accessed 14 May 2019].

22 English longitudinal study of ageing health and lifestyles of people aged 50 or over. Self-completion questionnaire. Available: https:// www.elsa-project.ac.uk/uploads/elsa/docs_w6/self_completion_ main.pdf [Accessed 14 May 2019].

23 National Health Service. Alcohol misuse. Available: www.nhs.uk/ conditions/alcohol-misuse

24 Masnoon N, Shakib S, Kalisch-Ellett L, et al. What is polypharmacy? A systematic review of definitions. BMC Geriatr 2017;17:230.

25 Peduzzi P, Concato J, Kemper E, et al. A simulation study of the number of events per variable in logistic regression analysis. J Clin Epidemiol 1996;49:1373-9.

26 Swalin A. How to handle missing data. Available: https:// towardsdatascience.com/how-to-handle-missing-data8646b18db0d4 [Accessed 17 May 2019].

27 Gerlach LB, Olfson M, Kales HC, et al. Opioids and other central nervous System-Active polypharmacy in older adults in the United States. J Am Geriatr Soc 2017;65:2052-6.

28 Bruggink L, Hayes C, Lawrence G, et al. Chronic pain: overlap and specificity in multimorbidity management. Aust $J$ Gen Pract 2019;48:689-92.

29 National Institute for Health and Care Excellence. Multimorbidity and polypharmacy, 2017. Available: https://www.nice.org.uk/advice/ ktt18/chapter/Key-points [Accessed 03 Jun 2020].

30 The King's Fund. Polypharmacy and medicines optimisation, 2013. Available: https://www.kingsfund.org.uk/sites/default/files/field/ field_publication_file/polypharmacy-and-medicines-optimisationkingsfund-nov13.pdf [Accessed 12 Dec 2019].

31 Ruscitto A, Smith BH, Guthrie B. Changes in opioid and other analgesic use 1995-2010: repeated cross-sectional analysis of dispensed prescribing for a large geographical population in Scotland. Eur J Pain 2015;19:59-66.

32 Stuhec M, Serra-Mestres J. Antidepressant drugs for older patients on polypharmacy: a systematic review reveals best evidence for sertraline. Global Psychiatry 2018;1:17-24.

33 Auret K, Schug SA. Underutilisation of opioids in elderly patients with chronic pain. Drugs Aging 2005;22:641-54

34 Gers L, Petrovic M, Perkisas S, et al. Antidepressant use in older inpatients: current situation and application of the revised STOPP criteria. Ther Adv Drug Saf 2018;9:373-84

35 Arthur A, Savva GM, Barnes LE, et al. Changing prevalence and treatment of depression among older people over two decades. $\mathrm{Br} J$ Psychiatry 2020;216:49-54.

36 Craftman Åsa Gransjön, Johnell K, Fastbom J, et al. Time trends in 20 years of medication use in older adults: findings from three elderly cohorts in Stockholm, Sweden. Arch Gerontol Geriatr 2016;63:28-35.

37 Bartley EJ, Fillingim RB. Sex differences in pain: a brief review of clinical and experimental findings. $\mathrm{Br} J$ Anaesth 2013;111:52-8.

38 Mordecai L, Reynolds C, Donaldson LJ, et al. Patterns of regional variation of opioid prescribing in primary care in England: a retrospective observational study. Br J Gen Pract 2018;68:e225-33.

39 Opioid prescribing highest in more deprived regions of England. The Pharmaceutical Journal 2019;302.

40 Dorner TE, Muckenhuber J, Stronegger WJ, et al. The impact of socio-economic status on pain and the perception of disability due to pain. Eur J Pain 2011;15:103-9.

41 Slater N, Rowley C, Venables RH, et al. Evaluating associations between metabolic health, obesity and depressive symptoms: a prospective analysis of data from the English longitudinal study of ageing (ELSA) with a 2-year follow-up. BMJ Open 2018;8:e025394. 